\section{Physics school education in}

\section{Finland}

Maija Ahtee

Department of Teacher Education, University of Jyväskylä

\section{General description of the status of physics at school}

Primary school or the lower stage of the comprehensive school

7 the comprehensive school is divided into lower stage (years 1 to 6 , average ages 7 to 12) and upper stage (years 7 to 9 , average ages 13 to 15 ). The distribution of minimum curriculum hours over six years at the lower stage is as follows: mother tongue (Finnish or Swedish) 23.5\%, mathematics $16.2 \%$, environment and nature study (containing science and focussing mainly on biological and geographical items) $11.0 \%$ of the total of 136 hours. At the lower stage teachers are usually class teachers who teach all the subjects. The class teacher education programme leads to a Master's degree (160 study weeks (sw)) with pedagogy as its main subject, and takes in practice approximately 5 years. The programme includes also basic studies in the subjects taught in primary schools (altogether $40 \mathrm{sw}$ ) and specialisation in two teaching subjects ( 15 sw each).

However, the students in class teacher education are not selected based on their interest or abilities in mathematics and science but on their interest for example in music or physical exercises. Furthermore, the class teacher education programme consists of very little guidance on how mathematics and science could be taught. Thus the basic studies in physics are limited to those at the upper stage of the comprehensive school. Neither mathematics nor sciences are among the popular specialisation subjects. During the years 1995-1997 from all the specialisation courses taken by the future class teachers only $10 \%$ dealt with mathematics, science or technology. Thus the class teachers as a whole have a serious deficiency in how to teach mathematics and science in a stimulating and challenging way, as well as in their content knowledge in these subjects.

\section{The upper stage of the comprehensive school}

At the upper stage, teaching of physics is in the hands of the subject teachers who have carried out at least $70 \mathrm{sw}$ in their main subject (physics, mathematics or chemistry), 35 sw in the second subject and $35 \mathrm{sw}$ in pedagogy, including practical teacher training. The $35 \mathrm{sw}$ studies in pedagogy including practical teacher training, give the teacher trainees competence to teach in all the school forms, from primary to upper secondary and vocational schools, all the subjects in which

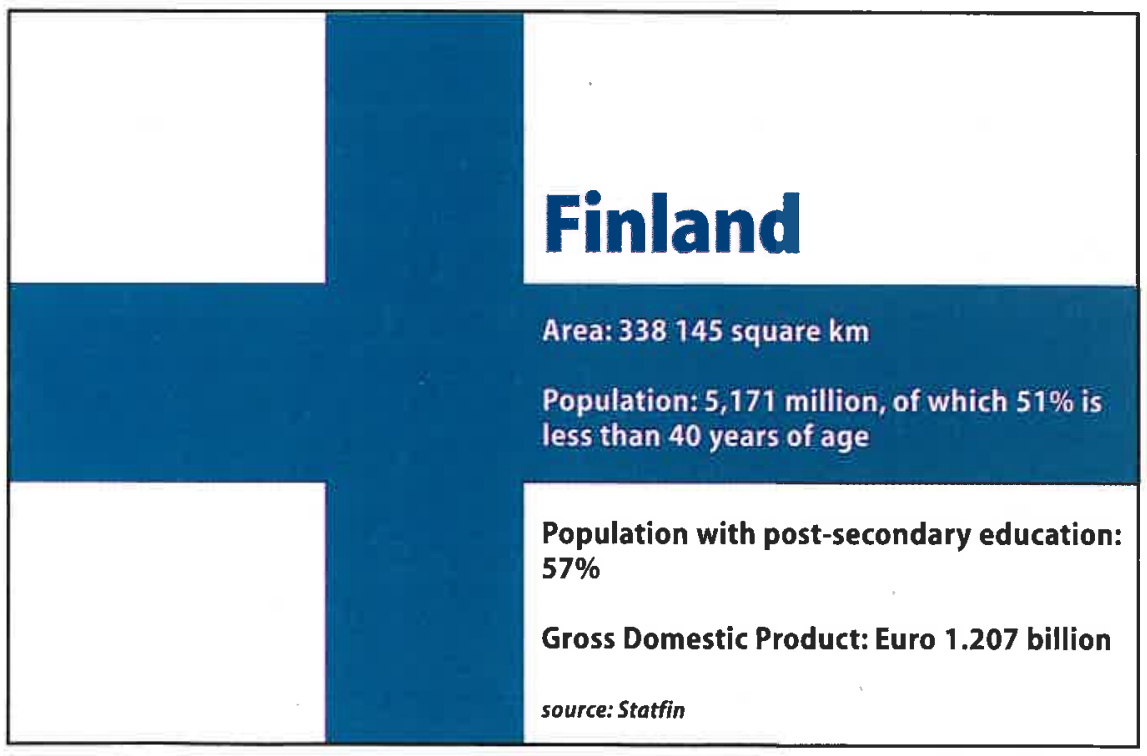

they have carried out the basic 35 sw studies. However, in the upper stage of the comprehensive school and in the upper secondary schools the physics teachers usually teach all the three subjects mathematics, physics and chemistry and in many cases they also take care of the needs in information technology. Most teachers (94\%) are employed full-time as municipal civil servants. They participate in inservice training for a minimum of three days a year.

The latest decision concerning the distribution of hours in comprehensive school and the curricular guidelines have increased significantly the opportunities for schools and local authorities to profile teaching. Schools are free to vary the weight and grouping of individual subjects by allocating teaching resources within the general framework of government financing. At the upper stage the distribution of minimum compulsory curriculum hours over three years is: mother tongue $11.4 \%$, mathematics $12.9 \%$, biology and geography $10.0 \%$, physics and chemistry $8.6 \%$ of the total of 70 hours. Thus less than a third of mathematics teaching in the comprehensive school is covered by the mathematics teacher.

\section{Upper secondary or senior secondary schools}

Recently, upper secondary education (years 10 to 12 , average ages 16 to 18 ) has progressed towards a highly decentralised system. The responsibility for teaching arrangements, course content and the selection of teaching material, is passed to the schools, and the cooperation of the schools with vocational institutions is highly recommended. Teaching is organised into courses, each course consisting of 38 lessons of 45 minutes each. The school year is divided into five or six periods and each period has a different study plan and concentrates on a selection of subjects. The order and placement of courses are left for the schools and pupils to decide. The upper secondary school leads to the national matriculation examination which mainly takes place at the end of spring term of the third school year but it can be spread out. Upper secondary school teachers have the same academic degree as upper stage comprehensive school teachers. The teachers who teach advanced courses in physics have mainly as their principal subject either physics or mathematics and the other as the second subject.

Upper secondary school studies consist of compulsory studies, advanced studies and applied studies. The school must pro- 
vide the advanced studies for the student to choose from. In physics there is one compulsory course which is the same for all the students. In addition, the school has to offer at least 7 advanced courses in physics. The students can decide how many advanced courses they want to take and in principle also in which order. The present situation is some kind of reconciliation after a long dispute on how to settle the conflict between physics for everybody and physics for those who want to continue in science related studies at the university level. An ample $60 \%$ of new students will yearly start in upper secondary schools. From them 20 to $25 \%$ will take advanced courses in physics. And from these about $20 \%$ are girls.

The matriculation examination is set and assessed nationally at the same time countrywide, twice a year in the spring and in the autumn. About half of the age group of 19 year-olds takes part in the examination. The different parts of the examination may be completed either at the same time or spread over three successive occasions. The compulsory subjects are mother tongue (Finnish, Swedish or Sá$\mathrm{mi}$ ), the second official language (Finnish or Swedish), one foreign language, and either mathematics or science and humanities. The latter comprises about 70 questions in several subjects. The student can answer the maximum of eight questions with any combination of questions and subjects. The subjects are religion, psychology, philosophy, ethics, history, civics, physics, chemistry, biology and geography. In physics alone there are 16 questions from which the student can choose. Each question is given 0 to 6 points. The total average achieved in all the physics questions varies around 3.6 points. About $20 \%$ of the students who take part in the matriculation examination answer at least one question in physics. About $10 \%$ of the students who answer the physics questions are girls. The total average of all the physics questions answered by girls is about 0.20 points less than the total average obtained by the boys.

In the earlier 1985 physics curriculum for the upper secondary school, the position of laboratory work was not specified. For example no extra time was allocated for practical work. Unfortunately, this was interpreted in most schools as a reason for giving up all kind of experimental work. In the new schools no facilities were reserved for physics laboratories and money was not given for equipment. However, the new 1994 curriculum stresses the experimental nature of physics and especially in the obligatory course, the experimental method is central. Also in many physics problems in the matriculation examination the experimental view is asked. However, there are still problems with proper laboratories and equipment. In-service training projects which focus on the experimental method and use of the computer as measuring apparatus have been launched for physics teachers. A central question is still how to get the physics teachers to use demonstrations and experiments during the lessons. The general difficulty remarked by physics teachers is how to find time enough to go through all the material in the text-books and also do experimental work.

\section{Vocational schools and institutes of technology}

The vocational schools provide initial vocational training to pupils aged 16 to $19+$. Vocational schools are developed towards larger, multidisciplinary institutions. Most vocational institutions operate both at secondary and post-secondary level. Institutes of technology provide only post-secondary education. Basic vocational qualifications require 2 to 3 years to complete. Basic qualifications comprise general studies, common core studies and subjects aimed at specialisation. Vocational training includes both practical training at school and on-the-job instruction. The number of new students is about $75 \%$ of the age group. This is explained by the fact that of the students matriculating from upper secondary school, about one-third go on to traditional multidisciplinary universities, universities of technology or other specialised universities, while twothirds continue at vocational institutions or vocational high schools. The ratio of the number of new students in tertiary education in sectors in which knowledge of physics is demanded to the total number of new students is at least $30 \%$. There are thus $10 \%$ more study places than students who have studied physics at the upper secondary schools.

\section{Two innovations}

\section{Joint national action}

Already the former Finnish government declared in its programme the necessity to raise mathematical and scientific knowledge and know-how in Finland to the international standard. Many representatives of Finnish industry have expressed their profound concern on the low level of knowledge and interest in mathematics and sciences among young people. For ex- ample, the director general of Nokia, Jorma Ollila, made in the main Finnish newspaper in October 1999 an appeal to the authorities to continue the actions in constructing and strengthening the knowledge resources. "Those countries that will specialize in knowledge intensive fields will be successful in future."

A joint Finnish endeavour has started under the direction of the Ministry of Education and the National Board of Education. A number of different bodies such as industrial organisations, subject teacher associations and universities have taken up the challenge and started a number of supporting actions and projects which lead to the same goals. The need to develop knowledge and skills in mathematics and sciences is seen to arise from the demands of the information society, the growth of high-tech enterprises, the need to secure sustainable development, and the citizens' need to master everyday technology. The major problems are seen as follows: Too few pupils opt for physics courses in school, and the learning outcome is inadequate as regards experimental skills, too few subject teachers have majored in physics, and too few women study physics or technology. A development and information network of 25 municipalities and six teacher training schools have been created. Some of the targets and actions are as follows:

The combined intake in universities and polytechnics in the fields of natural sciences and technology will be increased; Pupils will gain sound versatile knowledge and skills in mathematics and sciences to the extent that Finland will be in the top quarter in OECD comparisons;

Gender equality will be improved;

Finland will take regularly part in international comparisons of educational achievement in mathematics and sciences; Pupils will be trained systematically for international mathematics and physics olympiads;

The graduate school intended for mathematics, physics and chemistry teachers will be expanded;

In-service training will be arranged.

According to an intermediate evaluation of the progress of the joint national action in 1999, the communities, universities and teachers have responded very well to these ideas. However, the demand of young people for a proper education for example in physics in upper secondary school has increased so much during the last years that the earlier targets have turned out to be too small. The final evaluation will be published in 2002 . 